Note

\title{
Antimicrobial Activity of Protamine against Oral Microorganisms
}

\author{
YEON-HEE KIM ${ }^{1}$, SANG MOO KIM², AND SI YOUNG LEE ${ }^{1 *}$ \\ 'Department of Microbiology and Immunology, College of Dentistry, Research Institute of Oral \\ Science - Gangneung-Wonju National University, Gangneung 210-702, Korea \\ ${ }^{2}$ Department of Marine Food Science and Technology - Gangneung-Wonju National University, \\ Gangneung 210-702, Korea
}

Received 16 January, 2014/Accepted 21 November, 2014

\begin{abstract}
Protamine is an arginine-rich polycationic protein extracted from sperm cells of vertebrates including fishes such as salmon. The purpose of this study was to investigate the suppressive effects of protamine on the growth of oral pathogens for possible usage in dental materials. Minimal inhibitory concentration (MIC) and minimal bactericidal concentration (MBC) were determined by the microdilution method. Twelve strains of oral viridans streptococci, Actinomyces naes/undii, Actinomyces odontolyticus, Enterococcus faecalis, Lactobacillus acidophilus, Aggregatibacter actinomycetemcomitans, Fusobacterium nucleatum, Porphyromonas gingivalis and Candida albicans were suppressed by protamine. MIC and MBC values were between $0.009 \sim 20 \mathrm{mg} / \mathrm{mL}$ and $0.019 \sim 80 \mathrm{mg} / \mathrm{mL}$, respectively. The bactericidal activities of protamine against susceptible bacterial species were dependent on the concentration of protamine and incubation time. Based on the results of this study, protamine would be a useful compound for the development of antimicrobial agents against oral pathogens in dental materials.
\end{abstract}

Key words : Antimicrobial agent / Bacteria / Protamine / Salmon.

The emergence of antibiotic-resistant bacterial strains has led to an increased attempt to develop alternative antimicrobial agents (Baltzer and Brown, 2011). Recently, nonantibiotic compounds such as antibacterial peptides have been widely investigated. Different kinds of small cationic peptide a with broad-spectrum antibacterial activity such as defensin NP-1 and magainin 1 play an important role in the innate immune system of various animal species (Cederlund et al., 2011).

Protamine is a series of arginine-rich cationic polypeptides extracted from the sperm cells of vertebrates including fishes such as a salmon (Ando et al., 1973). Protamine is used in medicine as an antidote to heparin (Jaques, 1973) and as a carrier of insulin (Owens, 2011). Protamine/DNA complex has recently also been reported to be used for an injectable dental

*Corresponding author. Tel: +82-33-640-2455, Fax: +82-33642-6410, E-mail: siyoung (a)gwnu.ac.kr material (Fukushima et al., 2011). It has been reported that protamine has antimicrobial properties against a wide range of bacteria and yeasts. For example, Bacillus subtilis (Antohi and Popescu, 1979), Salmonella Typhimurium (Aspedon and Groisman, 1996), Escherichia coli (Hansen and Gill, 2000) and Candida utilis (Yphantis et al., 1967) have been shown to be sensitive to protamine. Johansen et al. (1995) reported that protamine from salmon killed Grampositive bacteria and significantly inhibited the growth of Gram-negative bacteria. Richards et al. (1990) reported that protamine depressed the metabolic activity of Staphylococcus epidermidis in a biofilm.

Oral bacterial species cause several different types of diseases. For example, mutans group streptococci are known as etiological bacterial species for dental caries (Hamada and Slade, 1980) and some Gram-negative anaerobic bacteria have been suggested to cause periodontal diseases (Haffajee and Socransky, 1994). Even though protamine has antimicrobial activities 
against some oral microbial species such as Porphyromonas gingivalis, Prevotella intermedia, Aggregatibacter actinomycetemcomitans and Candida albicans (Miura et al., 2010a; Miura et al., 2010b), it is rare to find studies on the antimicrobial activity of protamine against oral microorganisms. The purpose of this study was to investigate the antimicrobial effect of protamine on a wide range of oral microbial species in consideration of its possible usage in dental materials.

Streptococcus gordonii DL1, Streptococcus rattus BHT, Streptococcus mutans ATCC 25175 , Streptococcus sobrinus 6715 and Streptococcus sanguinis ATCC 10556 were laboratory strains stocked in Department of Microbiology and Immunology, College of Dentistry, Gangneung-Wonju National University. S. mutans KN405, S. sanguinis KN420, Streptococcus anginosus KN427, Streptococcus intermedius KN433, Streptococcus constellatus KN436, Streptococcus salivarius KN440 and Streptococcus oralis KN444 were isolated strains from Korean dental plaque and stocked in the same laboratory. Actinomyces naes/undii CCUG 35333T, Actinomyces odontolyticus ATCC 17929, C. albicans KCTC 7270, Enterococcus faecalis KCTC 3206, E. faecalis KCTC 2011, Lactobacillus acidophilus ATCC 4355, A. actinomycetemcomitans ATCC 33384, Fusobacterium nucleatum ATCC 23726 and $P$. gingivalis ATCC 33277 were obtained from the Korean Collection for Oral Microbiology (Chosun University, Gwangju, Korea).

Oral streptococci were grown in brain heart infusion broth (BHI) (Becton, Dickinson and Company, Sparks, $\mathrm{MD}$, USA) for $18 \mathrm{~h}$ at $37^{\circ} \mathrm{C}$ in aerobic conditions supplemented with $5 \% \mathrm{CO}_{2}$. Actinomyces were cultured in $\mathrm{BHI}$ for $18 \mathrm{~h}$ at $37^{\circ} \mathrm{C}$ under anaerobic conditions (Bactron Anaerobic Chamber, Sheldon Manufacturing Inc. Cornelius, Oregon, USA) with an atmosphere of $90 \% \mathrm{~N}_{2}, 5 \% \mathrm{CO}_{2}$ and $5 \% \mathrm{H}_{2}$. Lactobacillus were grown in lactobacillus MRS medium (Becton, Dickinson and Company, Sparks, MD, USA) for $18 \mathrm{~h}$ at $37^{\circ} \mathrm{C}$ in aerobic conditions supplemented with $5 \% \mathrm{CO}_{2}$, and enterococcus were grown in $\mathrm{BHI}$ for $18 \mathrm{~h}$ at $37^{\circ} \mathrm{C}$ under aerobic conditions. A. actinomycetemcomitans was inoculated in $\mathrm{BHI}$ broth and F. nucleatum and $P$. gingivalis were cultured in prereduced trypticase soy broth (Becton, Dickinson and Company) containing 1 $\mathrm{mg} / \mathrm{mL}$ of yeast extract (Becton, Dickinson and Company), $5 \mu \mathrm{g} / \mathrm{mL}$ of hemin (Sigma Chemical Co., St. Louis, MO, USA) and $1 \mu \mathrm{g} / \mathrm{mL}$ of menadione (Sigma Chemicals Co.). These three species were incubated in anaerobic conditions (Bactron Anaerobic Chamber) with an atmosphere of $90 \% \mathrm{~N}_{2}, 5 \% \mathrm{CO}_{2}$ and $5 \% \mathrm{H}_{2}$. Sabouraud Dextrose medium (Becton, Dickinson and Company) was used for culturing $C$. albicans which was incubated for $18 \mathrm{~h}$ at $25^{\circ} \mathrm{C}$ under aerobic conditions. The culture media supplemented with bacteriological agar were used for solid agar plates.

To determine the MIC of protamine, a stock solution of protamine sulfate from salmon (Sigma-Aldrich Chemical Co.) was prepared in microbial culture medium for each microbial species (final concentration $80 \mathrm{mg} / \mathrm{mL}$ ). Stock solution was filter sterilized. The MICs were determined by a microdilution method in culture medium which was modified from methods for antimicrobial susceptibility tests of the Clinical and Laboratory Standards Institute (CLSI) (2009). Using a microbial culture in the late log phase or stationary phase, a suspension equivalent to that of approximately $1 \times 10^{8} \mathrm{CFU} / \mathrm{mL}$ in each microbial culture medium was prepared. The bacteria were inoculated into serially diluted protamine solutions in 96-well round bottom microtitration plates for final concentrations of $5 \times 10^{5}$ $\mathrm{CFU} / \mathrm{mL}$. The final volume was $100 \mu \mathrm{L}$ in a microtitration plate well. The microdilution trays were incubated in the same conditions described in bacterial culture conditions. MICs of protamine against aerobic and anaerobic bacteria were determined after incubation for 18 and $48 \mathrm{~h}$, respectively. The microtitration plates were read visually and the minimum concentration of protamine showing no turbidity was determined as the MIC. MBC of protamine was determined by taking a $100 \mu \mathrm{L}$ culture medium of each

TABLE 1. MIC and MBC of protamine against oral microorganisms.

\begin{tabular}{|c|c|c|}
\hline \multirow{2}{*}{ Microorganism } & \multicolumn{2}{|c|}{ Protamine } \\
\hline & $\mathrm{MIC}^{\mathrm{a}}$ & $\mathrm{MBC}^{\mathrm{a}}$ \\
\hline S. anginosus KN427 & 5 & 20 \\
\hline S. constellatus KN436 & 5 & 10 \\
\hline S. gordonii DL1 & 0.625 & 0.625 \\
\hline S. intermedius KN433 & 1.25 & 1.25 \\
\hline S. mutans ATCC 25175 & 0.009 & 0.019 \\
\hline S. mutans KN405 & 0.078 & 0.156 \\
\hline S. oralis KN444 & 1.25 & 1.25 \\
\hline S. rattus BHT & 5 & 20 \\
\hline S. salivarius KN440 & 0.625 & 1.25 \\
\hline S. sanguinis ATCC 10556 & 1.25 & 2.5 \\
\hline S. sanguinis KN420 & 1.25 & 2.5 \\
\hline S. sobrinus 6715 & 0.039 & 0.625 \\
\hline A. naes/undii CCUG 35333T & 1.25 & 10 \\
\hline A. odontolyticus ATCC 17929 & 0.625 & 1.25 \\
\hline L. acidophilus ATCC 4355 & 2.5 & 10 \\
\hline E. faecalis KCTC 3206 & 2.5 & 40 \\
\hline E. faecalis KCTC 2011 & 2.5 & 80 \\
\hline A. actinomycetemcomitans ATCC 33384 & 20 & 40 \\
\hline F. nucleatum ATCC 23726 & 5 & 5 \\
\hline P. gingivalis ATCC 33277 & 5 & 10 \\
\hline C. albicans KCTC 7270 & 1.25 & 5 \\
\hline
\end{tabular}

${ }^{\mathrm{a}} \mathrm{mg} / \mathrm{mL}$. 
bacterial species from the wells showing no visible growth and spreading it onto agar plates. The agar plates were incubated for 3 days for aerobic bacteria and 7 days for anaerobic bacteria. The MBC was defined as the minimum concentration of protamine that showed $\geq 99.9 \%$ reduction of the original inoculums. The experiments for determining MIC and MBC were repeated at least three times. We checked the MIC and MBC of chlorhexidine (Sigma-Aldrich Chemical Co.) as positive controls.

Among bacterial species tested in this study, $S$. mutans KN405, S. sobrinus 6715, L. acidophilus ATCC 4355 and A. odontolyticus ATCC 17929, which were known to be related to the initiation and progress of dental caries, were selected for the further experiments. For examining the effects of concentrations of protamine, serially diluted protamine was added in wells containing bacteria and then incubated for $1 \mathrm{~h}$. In another set of experiments, the effect of incubation time on the killing of bacteria by protamine was investigated by increasing the incubation time at the final protamine concentration of $10 \mathrm{mg} / \mathrm{mL}$. Each experimental group consisted of duplicate wells. After incubation, each sample was serially diluted with PBS and $100 \mu \mathrm{L}$ of diluents was spread on duplicate agar plates for each species of microorganism. The plates were incubated for $72 \mathrm{~h}$ at $37^{\circ} \mathrm{C}$ for each species and then the number of CFU was determined by an automatic colony counter (IUL, Barcelona, Spain).

For examining the effect of protamine on the bacterial surface structure, S. mutans, one of the major etiological agents for inducing dental caries, was used. Variable pressure field emission scanning electron microscopy (VP-FE-SEM) SUPRA55VP (Carl Zeiss, Oberkochen, Germany) was used to examine the morphological changes in the S. mutans KN405. The bacteria were treated with $1 \mathrm{mg} / \mathrm{mL}$ of protamine for 4 $\mathrm{h}$ at $37^{\circ} \mathrm{C}$ and then centrifuged at $10,000 \times \mathrm{g}$. Bacterial pellets were fixed in $2.5 \%$ glutaraldehyde in PBS $(\mathrm{pH}$ 7.4) for $1 \mathrm{~h}$ at room temperature. The fixed samples were then washed three times with PBS for $10 \mathrm{~min}$ and dehydrated for $30 \mathrm{~min}$ in a graded series of ethanol. After critical point drying, the samples were mounted on stubs, coated with gold and observed with SEM.

The Kruskal-Wallis test was used to compare the effects of the incubation time and the protamine concentration on bacterial killing. The level of significance was $P<0.05$. Correlations between bacteria killing and the incubation time or protamine concentration were evaluated by calculating Spearman's rank correlation coefficient (Spearman's rho). The statistical analysis was performed using the Software Package for Social Sciences (SPSS, version 20.0, IBM Inc., USA).
Twelve strains of oral viridans streptococci, $A$. naes/undii, $A$. odontolyticus, E. faecalis, $L$. acidophilus, A. actinomycetemcomitans, F. nucleatum, P. gingivalis and $C$. albicans were used in this study. The MIC of protamine against oral streptococci was lower than 5 $\mathrm{mg} / \mathrm{mL}$. MICs for $A$. naes/undii and A. odontolyticus were 1.25 and $0.625 \mathrm{mg} / \mathrm{mL}$, respectively. The MIC for lactobacillus was $2.5 \mathrm{mg} / \mathrm{mL}$ and MICs for periodontopathogens such as $P$. gingivalis and $F$. nucleatum were $5 \mathrm{mg} / \mathrm{mL}$. The MIC for S. mutans ATCC 25175 was the lowest $(0.009 \mathrm{mg} / \mathrm{mL})$ followed by those for $S$. sobnirus $6715(0.039 \mathrm{mg} / \mathrm{ml})$ and $S$. mutans strain $\mathrm{KN} 405(0.078 \mathrm{mg} / \mathrm{mL})$ in that order. A. actinomycetemcomitans showed the highest MIC (20 $\mathrm{mg} / \mathrm{mL}$ ) among the microbial strains examined in this experiment. C. albicans, the only eukaryotic cell used in this study, also showed a low MIC $(1.25 \mathrm{mg} / \mathrm{mL})$ comparable to oral bacterial strains. The MIC and MBC values of chlorhexidine for the bacterial strains used in this study were $0.001 \sim 15.6 \mu \mathrm{g} / \mathrm{mL}$ and $0.001 \sim 62.5$ $\mu \mathrm{g} / \mathrm{mL}$, respectively. These values were similar to the values for oral bacteria reported in another study (Emilson, 1977).

The effects of protamine concentration and incubation time on the bactericidal activity against oral bacteria were examined by using $S$. mutans KN405, $S$. sobrinus 6715, L. acidophilus ATCC 4355 and $A$. odontolyticus ATCC 17929. The bactericidal activities of protamine depended on the concentration of protamine and incubation time (Fig. 1a-d). Incubation with protamine for $90 \mathrm{~min}$ at $10 \mathrm{mg} / \mathrm{mL}$ inhibited the growth of S. mutans KN405 by $61 \%$ (Fig. 1a). Protamine also suppressed the growth of $A$. odontolyticus by $85 \%$ after incubation for 90 min (Fig. 1d). The difference in the CFU values as a function of the incubation time with protamine was statistically significant for all species of bacteria used in this study $(P<0.05)$ (Fig. 1$)$. There were significant negative correlations between the CFU values and the incubation time for $S$. mutans $(R=$ $-0.715, P<0.01)$, S. sobrinus $(R=-0.922, P<0.01)$, L. acidophilus $(R=-0.723, P<0.01)$ and $A$. odontolyticus $(\mathrm{R}=-0.946, P<0.01)$. At 1.25 and 10 $\mathrm{mg} / \mathrm{mL}$ of protamine, the number of $S$. mutans cells was reduced by 42 and 68\%, respectively (Fig. 1a). Protamine at 1.25 and $10 \mathrm{mg} / \mathrm{mL}$ suppressed the growth of $S$. sobrinus by 30 and $53 \%$, respectively (Fig. 1b). Protamine killed A. odontolyticus by $98 \%$ at $5 \mathrm{mg} /$ $\mathrm{mL}$ (Fig. 1d). The difference in the CFU values as a function of the concentration of protamine was statistically significant for four species of bacteria used in this study $(P<0.05)$ (Fig. 1). The CFU values of $S$. mutans $(R=-0.892, P<0.01)$, S. sobrinus $(R=$ -0.896, $P<0.01)$ and $A$. odontolyticus $(R=-0.946, P$ $<0.01$ ) had significant negative correlations with the 
(a) S. mutans KN405
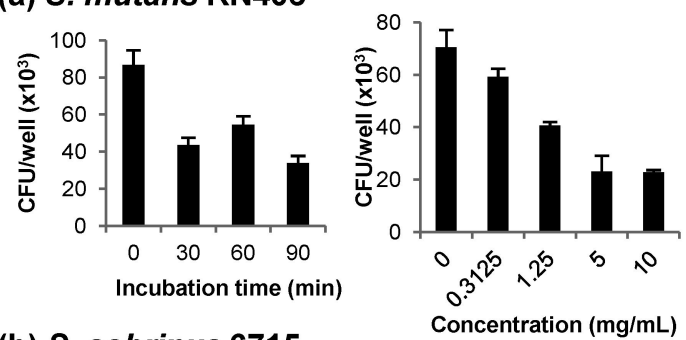

(b) S. sobrinus 6715
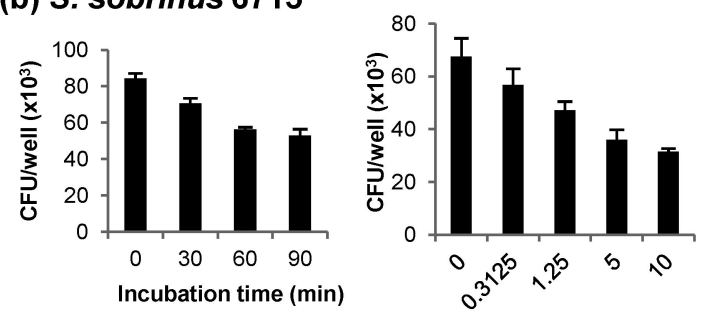

(c) L. acidophilus ATCC 4355
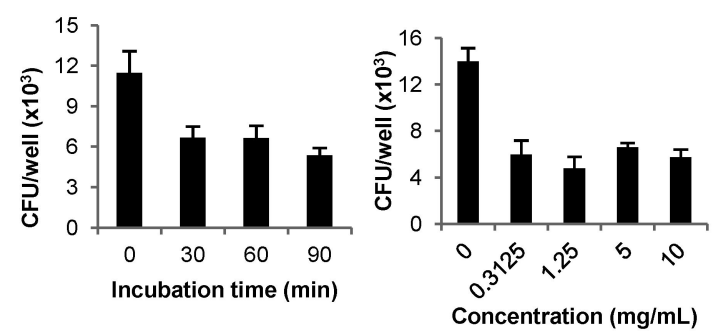

(d) A. odontolyticus ATCC 17929
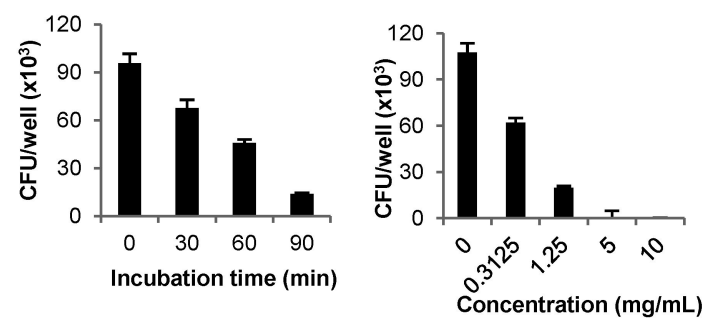

FIG. 1. Effects of the concentration of protamine and incubation time on the killing of bacteria. Values indicate means of duplicate determinations; standard deviations of the mean (error bars) are indicated by vertical lines.

concentration of protamine. The number of $L$. acidophilus CFUs and the concentration of protamine were not negatively correlated in a significant way $(R=$ $-0.344, P=0.138$ ).

S. mutans KN405 was observed by SEM after treatment with $1 \mathrm{mg} / \mathrm{mL}$ of protamine for $4 \mathrm{~h}$ at $37^{\circ} \mathrm{C}$ (Fig. 2b). The protamine treatment modified the cell surface texture of the bacteria. Small bumps appeared on the surface of $S$. mutans after treatment with protamine.

In this study, oral microbial species related to oral diseases and frequently discovered from dental plaque
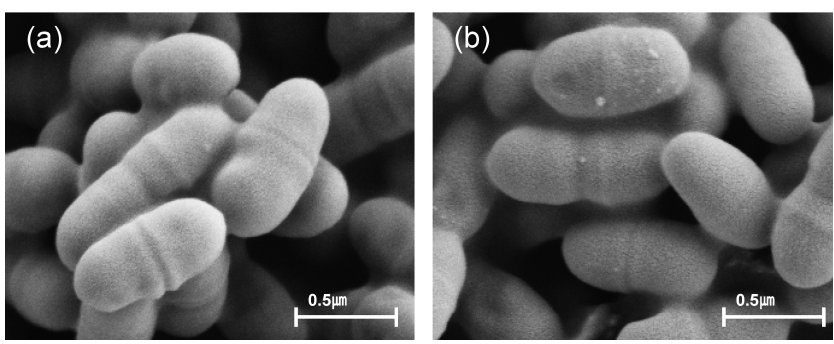

FIG. 2. Scanning electron microscopy (SEM). (a) untreated bacteria, (b) bacteria treated with protamine.

were selected for the determination of the antimicrobial activity of protamine. S. mutans and S. sobrinus are known as causative agents for dental caries and lactobacilli also play a role in the progress of dental caries (Hamada and Slade, 1980). We examined some mitis group streptococci such as $S$. sanguinis and $S$. gordonii as initial colonizers in dental plaque formation (Coykendall, 1989). Actinomyces are found at root caries lesions (Bowden, 1990) and E. faecalis is related to endodontic infections (Kayaoglu and Orstavik, 2004). We also examined bacterial species, such as Aggregatibacter, Fusobacterium and Porphyromonas, which were suggested as causative agents for periodontal diseases. In this study, protamine had antibacterial activity against laboratory strains as well as freshly isolated strains. The MICs for mutans group streptococci, causative agents for dental caries, were much lower than those for other species. On the other hand, MICs of protamine against periodonto-pathogens such as $P$. gingivalis, $F$. nucleatum and $A$. aggregatibacter were higher than those against other oral species. In this study, the growth of $A$. actinomycetemcomitans appeared to be less affected by protamine in our susceptibility test. At present, we do not know what factors may contribute to protamine having a higher MIC it than against other strains of oral bacteria. Interestingly, higher MICs and MBCs of antibacterial decapeptides against $A$. actinomycetemcomitans were reported than against other species of oral bacteria (Concannon et al., 2003).

The antibacterial effect of most polycationic peptides is generally related to their ability to disrupt the bacterial cell wall (Vaara, 1992). The action mechanism of the antimicrobial activity of protamine is suggested to be the electrostatic attraction between the positively charged protamine molecule and the negatively charged cell envelope, causing the inhibition or killing of bacteria due to the leakage of $\mathrm{K}^{+}$, ATP and intracellular enzymes (Johansen et al., 1997; Stumpe and Bakker, 1997). Another study indicated that protamine disrupted energy transduction and nutrient uptake functions, and 
suggested that the cytoplasmic membrane was the target of protamine action (Aspedon and Groisman, 1996). However, all possible antibacterial mechanisms of protamine have not been disclosed yet and the killing mechanism of protamine against bacteria has been suggested to be different among bacterial species (Johansen et al., 1996). In the present study, changes in the surface of bacteria were observed by SEM after treatment with protamine. The bacterial surface change might be related to the mechanisms underlying the bactericidal effects of protamine. However, the morphological alteration of bacterial surfaces by protamine treatment was not very dramatic in this study.

Darouiche et al. (2008) reported that the combination of chlorhexidine and protamine had a synergistic inhibitory effect on E. coli and there was also a significant synergistic antibiofilm and antimicrobial activity against $E$. coli, Pseudomonas aeruginosa and $S$. epidermidis. The combination of protamine and chlorhexidine could be applied for the induction of synergistic antibacterial effects against oral bacterial species. Chlorhexidine has broad-spectrum antibacterial activity where its inhibition mechanism is partly from the disruption of the bacterial plasma membrane (Kuyyakanond and Quesnel, 1992). Protamine can increase the permeability of bacterial cell membrane, thereby facilitating the transport of chlorhexidine into the cytoplasm (Antohi and Popescu, 1979; Aspedon and Groisman, 1996).

The effect of protamine on the formation of bacterial biofilms was reported previously (Richards et al., 1990; Soboh et al., 1995). The combination of protamine with rifampin against $S$. epidermidis biofilms demonstrated synergism and showed a totally bactericidal outcome (Richards et al., 1990). Soboh et al. (1995) reported that the synergism between ciprofloxacin and protamine significantly enhanced the efficacy of ciprofloxacin against planktonic bacteria and biofilm caused by $P$. aeruginosa. The present study tested the antimicrobial effects of protamine against planktonic bacteria rather than biofilm bacteria. Thus, the antibacterial effects of protamine on bacterial biofilms might differ from those obtained in this study using planktonic bacteria. Therefore, further studies are required to investigate the suppressive effects of protamine against oral biofilms.

Recently, Miura et al. (2010a; 2010b) reported the antibacterial and antifungal activity of protamine against oral microorganisms, where there was inhibition on the growth of $P$. gingivalis, $P$. intermedia and $A$. actinomycetemcomitans and on the attachment of $C$. albicans to polymethyl methacrylate. The MIC of protamine for $P$. gingivalis was lower than that in this study. It is assumed that the discrepancy between MICs of these studies might result from the differences in the method for determining MICs. They used agar plates containing protamine for determining MIC instead of the microdilution methods used in our study. Fukushima et al. (2010; 2011) developed a DNA/protamine complex paste for an injectable dental material. The antimicrobial activities of protamine against a wide variety of oral bacteria including cariogenic and periodontopathic bacteria in the present study may add advantages to the DNA/protamine-injectable dental material. Interestingly, protamine has been reported to inhibit the proteolytic activity of arginine-specific cysteine protease from $P$. gingivalis (Kontani et al., 1999). Protamine was also capable of binding strongly to $P$. gingivalis fimbriae and inhibited fimbrial interaction with immobilized fibronectin, which resulted in inhibiting the binding of $P$. gingivalis to host the surface (Kontani et al., 1999). These inhibitory characteristics of protamine against the virulence factors of $P$. gingivalis for inducing periodontal diseases would play a helpful role when protamine is added to dental care products.

In this study, protamine from salmon had antimicrobial activity against a wide range of oral pathogenic microbial species. The bactericidal activities of protamine against susceptible bacterial species were dependent on the concentration of protamine and incubation time. These findings might facilitate the possibility of using protamine in dental materials.

\section{ACKNOWLEDGEMENTS}

This work was supported by grant No. RTI05-01-02 from the Regional Technology Innovation Program of the Ministry of Knowledge Economy (MKE).

\section{REFERENCES}

Ando, T., Yamasaki, M., and Suzuki, K. (1973) Protamines. Isolation, characterization, structure and function. Mol. Biol. Biochem. Biophys., 12, 1-114.

Antohi, S., and Popescu, A. (1979) Lethal effect of protamine and histone on competent Bacillus subtilis cells. Inhibition of genetic transformation by protamine in sublethal concentration. Mol. Gen. Genet., 170, 345-349.

Aspedon, A., and Groisman, E.A. (1996) The antibacterial action of protamine: evidence for disruption of cytoplasmic membrane energization in Salmonella Typhimurium. Microbiology., 142 ( Pt 12), 3389-3397.

Baltzer, S.A., and Brown, M.H. (2011) Antimicrobial peptides: promising alternatives to conventional antibiotics. J. Mol. Microbiol. Biotechnol., 20, 228-235.

Bowden, G.H. (1990) Microbiology of root surface caries in humans. J. Dent. Res., 69, 1205-1210.

Cederlund, A., Gudmundsson, G.H., and Agerberth, B. (2011) Antimicrobial peptides important in innate immunity. FEBS J., 278, 3942-3951.

Clinical and Laboratory Standards Institute, 2009. Methods for Dilution Antimicrobial Susceptibility Tests for Bacteria that Grow Aerobically, M07-A8, Vol.29, no.2, 8th ed. CLSI, 
Wayne, PA.

Concannon, S.P., Crowe, T.D., Abercrombie, J.J., Molina, C.M., Hou, P., Sukumaran, D.K., Raj, P.A., and Leung, K.P. (2003) Susceptibility of oral bacteria to an antimicrobial decapeptide. J. Med. Microbiol., 52, 1083-1093.

Coykendall, A.L. (1989) Classification and identification of the viridans streptococci. Clin. Microbiol. Rev., 2, 315-328.

Darouiche, R.O., Mansouri, M.D., Gawande, P.V., and Madhyastha, S. (2008) Efficacy of combination of chlorhexidine and protamine sulphate against device-associated pathogens. J. Antimicrob. Chemother., 61, 651-657.

Emilson, C.G. (1977) Susceptibility of various microorganisms to chlorhexidine. Scan. J. Dent. Res., 85, 255-265.

Fukushima, T., Ohno, J., Hayakawa, T., Imayoshi, R. Kawaguchi, M., Doi, Y., Kanaya, K., and Mitarai, M. (2010) Polycationic protamine for water-insoluble complex formation with DNA. Dent. Mater. J., 29, 529-535.

Fukushima, T., Ohno, J., Imayoshi, R., Mori, N., Sakagami, R., Mitarai, M., and Hayakawa, T. (2011) DNA/protamine complex paste for an injectable dental material. J. Mater. Sci. Mater. Med.

Haffajee, A.D., and Socransky, S.S. (1994) Microbial etiological agents of destructive periodontal diseases. Periodontol. 2000., 5, 78-111.

Hamada, S., and Slade, H.D. (1980) Biology, immunology, and cariogenicity of Streptococcus mutans. Microbiol. Rev., 44, 331-384.

Hansen, L.T., and Gill, T.A. (2000) Solubility and antimicrobial efficacy of protamine on Listeria monocytogenes and Escherichia coli as influenced by $\mathrm{pH}$. J. Appl. Microbiol., 88, 1049-1055

Jaques, L.B. (1973) Protamine-antagonist to heparin. Can. Med. Assoc. J., 108, 1291-1297.

Johansen, C., Gill, T., and Gram, L. (1996) Changes in cell morphology of Listeria monocytogenes and Shewanella putrefaciens resulting from the action of protamine. Appl. Environ. Microbiol., 62, 1058-1064.

Johansen, C., Gill, T., and Gram, L. (1995) Antibacterial effect of protamine assayed by impedimetry. J. Appl. Bacteriol., 78, 297-303.

Johansen, C., Verheul, A., Gram, L., Gill, T., and Abee, T.
(1997) Protamine-induced permeabilization of cell envelopes of gram-positive and gram-negative bacteria. Appl. Environ. Microbiol., 63, 1155-1159.

Kayaoglu, G., and Orstavik, D. (2004) Virulence factors of Enterococcus faecalis: relationship to endodontic disease. Crit. Rev. Oral Biol. Med., 15, 308-320.

Kontani, M., Amano, A., Nakamura, T., Nakagawa, I. Kawabata, S., and Hamada, S. (1999) Inhibitory effects of protamines on proteolytic and adhesive activities of Porphyromonas gingivalis. Infect. Immun., 67, 4917-4920.

Kuyyakanond, T., and Quesnel, L.B. (1992) The mechanism of action of chlorhexidine. FEMS Microbiol. Lett., 79, 211-215

Miura, T., Hayakawa, T., Okumori, N., Iohara, K., and Yoshinari, M. (2010a) Antifungal activity against Candida albicans on PMMA coated with protamine derivatives. J. Oral Tissue Eng., 8, 30-38.

Miura, T., Iohara, K., Kato, T., Ishihara, K., and Yoshinari, M. (2010b) Basic peptide protamine exerts antimicrobial activity against periodontopathic bacteria. J. Biomed. Sci. Eng., 3, 1069-1072.

Owens, D.R. (2011) Insulin preparations with prolonged effect. Diabetes Technol. Ther., 13 Suppl 1, S5-14.

Richards, G.K., Prentis, J., and Gagnon, R.F. (1990) The effect of protamine on antibiotic action against Staphylococcus epidermidis biofilms. ASAIO Trans., 36 M296-9.

Soboh, F., Khoury, A.E., Zamboni, A.C., Davidson, D., and Mittelman, M.W. (1995) Effects of ciprofloxacin and protamine sulfate combinations against catheter-associated Pseudomonas aeruginosa biofilms. Antimicrob. Agents Chemother., 39, 1281-1286.

Stumpe, S., and Bakker, E.P. (1997) Requirement of a large $\mathrm{K}^{+}$-uptake capacity and of extracytoplasmic protease activity for protamine resistance of Escherichia coli. Arch. Microbiol., 167, 126-136.

Vaara, M. (1992) Agents that increase the permeability of the outer membrane. Microbiol. Rev., 56, 395-411.

Yphantis, D.A., Dainko, J.L., and Schlenk, F. (1967) Effect of some proteins on the yeast cell membrane. J. Bacteriol., 94, 1509-1515. 